\title{
Equidad de Género, Medio Ambiente y Políticas Públicas
}

\author{
Gender Equity, Environment and Public Policies
}

Leticia Villamil-Navarrete $^{a}$

\begin{abstract}
:
This conceptual map generalizes the mainstreaming of the gender dimension into environmental public policies and the achievement of processes that lead to sustainable development, as well as challenges in adopting new approaches to development alternatives.

Keywords:

Sustainability, equity, public policies

\section{Resumen:}

En el presente mapa conceptual se generaliza la incorporación de la dimensión de género en las políticas públicas ambientales y la consecución de procesos que llevan a un desarrollo sustentable, así como retos en adoptar nuevos enfoques hacia alternativas de desarrollo.
\end{abstract}

\section{Palabras Clave:}

Sustentabilidad, equidad, políticas públicas

\section{Introducción}

Para comprender los conceptos expuestos en este mapa se requiere precisar los siguientes puntos:

Punto uno sustentabilidad, equidad y transversalidad: que se comprende por ejes para la incorporación del enfoque de género, para lograr el reconocimiento, valoración y participación de las mujeres ha sido uno de los retos más importantes en los procesos de apertura democrática, justicia social y derechos humanos, por lo que los movimientos sociales mundiales demandan equidad e igualdad dentro del marco de los principios de los derechos humanos.

Segundo punto en las políticas ambientales es necesario afrontar procesos para impedir:

-Políticas que no reflejen compromisos nacionales e internacionales con temas de los derechos humanos y equidad de género.

-Políticas que afecten negativamente a las mujeres, ejemplo las políticas agrarias.
-Reproducir desigualdades o Iniquidad ejemplo tenencia de la tierra y control de los recursos naturales.

-Dirigir acciones y participación sólo a una parte de la población, ejemplo conocimiento y acceso a tecnologías para hacerle frente a los fenómenos de degradación ambiental existentes, únicamente a los hombres, y

-Desigualdad.

Por lo que, si consideramos el concepto de desarrollo sostenible, equidad e integralidad formulado en el informe Brundtland, sustentan la necesidad y factibilidad de incorporar el enfoque de equidad de género en las políticas ambientales concepto que nos permite satisfacer nuestras necesidades sin comprometer la capacidad de las generaciones futuras para satisfacer sus propias necesidades; añadiríamos también la concepción de Paolo Bifani (1997) como un proceso dinámico, que tiene como meta garantizar un mayor bienestar de las sociedades presentes y futuras. Visto como un sistema complejo, compuesto de múltiples dimensiones: cultural, social, político, económico y ambiental. Potenciando el plano ideológico y práctico, favoreciendo la educación, formación, desarrollo científico y tecnológico, que

Autor de Correspondencia, Universidad Autónoma del Estado de Hidalgo, https://orcid.org/0000-0001-8208-185X Email: leticiav@uaeh.edu.mx 
contribuyan a disminuir brechas entre grupos favorecidos y marginados.

Tercer punto incorporación de la perspectiva de equidad de género en la política ambiental mexicana. Tenemos que En México el proceso de incorporación del enfoque de equidad en las políticas públicas inicia de manera institucional en 1995, con el programa nacional de la mujer: Alianza para la igualdad 1995-2000 cuyas siglas son (Pronam), marco en que las instancias públicas federales y estatales asumirían los compromisos para asegurar la mejoría de las condiciones de la mujer en el país, como La semarnap que adoptó 2 ejes de acción principales: 1) la obligatoriedad en el cumplimiento de los lineamientos señalados en el PRONAM 1995-2000 como son ( principios, actividades y medios para la ejecución del capítulo 24 de la Agenda 21 y del capítulo K de la Plataforma de Acción de la cuarta conferencia sobre la mujer en Beijing. Y 2) Impulso de demandas y gestiones hechas desde la Red Mujer y Medio Ambiente a partir de 1997. Para julio de 1998 se adopta el enfoque de equidad de género en las políticas públicas ambientales, con perspectiva de desarrollo sustentable bajo los parámetros de igualdad de oportunidades entre hombres y mujeres para decidir y participar para generar metodologías y construir indicadores.

Cuarto punto la declaración para la equidad de género, medio ambiente y sustentabilidad. Representa un Documento contundente y sencillo que manifestara la intencionalidad y compromiso de la institución respecto a la perspectiva de género, la equidad y el medio ambiente. En junio de 1999, México contaba ya con una Declaración para la Equidad de Género de la Secretaría de Medio Ambiente, Recursos Naturales y Pesca, basada en el marco legal nacional y los compromisos internacionales firmados por el gobierno mexicano.

Quinto punto la construcción del plan de acción. Con el apoyo en el planteamiento metodológico de la UNION y la Red Mujer y Medio Ambiente, se trabajó con 2 vertientes: la primera, asociada al quehacer interno de la institu ción y la $2^{2}$ referida a la inclusión de esta perspectiva en las políticas ambientales y de participación pública. La secretaría contaría con una política de desarrollo sustentable, explícitamente con enfoque de género, lo que implicaría lograr el equilibrio en el diseño y la aplicación de al menos 3 dimensiones del desarrollo sustentable: social, económico y ecológico. (Ruiz Mejía, 2003)

Por último, el cambio de administración. La nueva administración determina incidir y evaluar de manera transversal en todos los gabinetes y áreas del gobiemo federal. La Semarnap se convierte en Semarnat, en marzo de 2001 la Semarnat y el Inmujeres firman convenio de colaboración y establecen un programa de trabajo conjunto con la finalidad de institucionalizar la perspectiva de género en la política ambiental para el desarrollo sustentable, mediante acciones para la promoción, protección y difusión de los derechos de las mujeres y las niñas, tales como capacitación al sector y asesoramiento para la elaboración de indicadores.

\section{Los avances en la incorporación del enfoque de equidad de género.}

La variedad en los perfiles de los y las integrantes del comité ha constituido una riqueza de experiencias que incrementa las posibilidades de proyectos y acciones muy cercanas a procesos multidisciplinares e interdisciplinares.

\section{Conclusiones}

La inclusión de equidad de género tendrá que reflejarse no sólo en la población objetivo de las políticas públicas ambientales, es importante propiciar y mantener las condiciones de equidad en el interior, donde los servidores públicos, mujeres y hombres, valoren y fomenten hacia la población la toma de decisiones ambientales.

\section{Referencias}

[1] Ruiz Mejía, Dulce y López Ribera, Isabel (2003). Equidad de género, medio ambiente y políticas públicas: el caso de México y la Secretaría de Medio Ambiente y Recursos Naturales. Revista de Estudios de Género. La ventana,(17), 43-77. [Fecha de Consulta 6 de enero de 2020]. ISSN: $1405-$ $9436 . \quad$ Disponible

https://www.redalyc.org/articulo.oa $? \mathrm{id}=884 / 88401704$ 
Publicación semestral, Ingenio y Conciencia Boletín Científico de la Escuela Superior Ciudad Sahagún, Vol. 7, No. 14 (2020) 65-67 


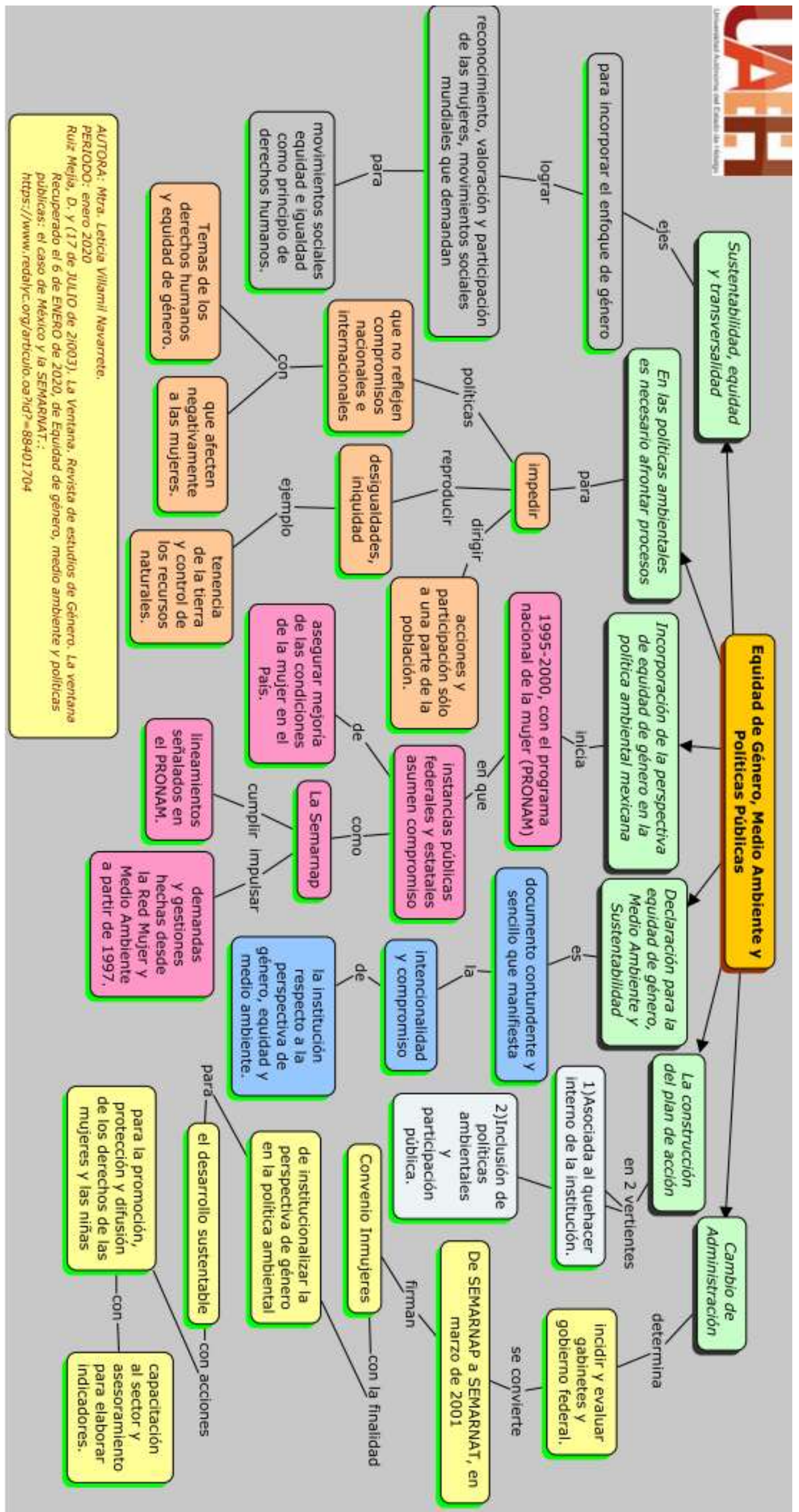

